\title{
Uma Reflexão sobre a Política na Pós-Modernidade ${ }^{1}$
}

\author{
Athili Laramo Castro de Lima
}

Mestre e Doutor em Direito, Professor de Direito e Sociedade e Sociologia do Direito da UFPR.

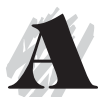

ntes de ingressar na abordagem da política na pós-modernidade ${ }^{2}$ é necessário resgatar como a política manifestava-se na modernidade, a fim de possibilitar o contraste das duas experiências.

A idéia de política moderna tem como referencial a peculiaridade de ser desenvolvida dentro de um espaço delimitado territorialmente, ou seja, os limites do Estado.

Podemos vislumbrar essa peculiaridade, a partir das teorias da soberania, consubstanciadas na soberania estatal, consoante as teorias de JEAN BODIN e de THOMAS HOBBES, na soberania popu- lar, segundo as idéias de JOHN LOCKE e JEAN-JACQUES ROUSSEAU e na soberania nacional, através das teorias de SIÈYES.

Todavia, as teorizações de MAX WEBER nos propiciarão uma leitura privilegiada da política na modernidade, ${ }^{3}$ a qual encontrava-se identificada com a delimitação territorial do Estado.

WEBER identifica como característica do Estado moderno a dominação racio nal, baseada na crença na legalidade das ordenações, fundada em regras racionalmente criadas, as leis. $\bigcirc$ Estado moderno seria um Estado racional, em face da forma racional de gerir o Estado, através de uma

1 Trabalho apresentado no Curso: Pós-Modernidade em Debate: ciência, política, direito e arte, realizado na Universidade Federal do Paraná de 11 a 15 de setembro de 2000.

2 SÉRGIO PAULO ROUANET, na obra As razões do iluminismo. São Paulo: Companhia das Letras, 1992, p. 231, questiona se a consciência de que algumas pessoas têm da ruptura da modernidade, efetivamente corresponde a uma ruptura real ao asseverar: "E o pós-moderno? Corresponderia a uma verdadeira ruptura? Reformulando a pergunta: partindo do princípio de que o pósmoderno se define, em sua acepção mais geral, por um questionamento da modernidade, no todo ou em parte, podemos dizer que estamos vivendo uma época de transição para a pós-modernidade?"

3 Neste sentido asseverou SÉRGIO PAULO ROUANET, op. cit., p. 231, que não há melhor guia para compreender a modernidade do que WEBER, aduzindo ainda que: "Como se sabe, para WEBER a modernidade é o produto do processo de racionalização que ocorreu no Ocidente, desde o final do século XVIII, e que implicou a modernização da sociedade e a modernização da cultura". 
administração racionalmente estabelecida, através da burocracia e de uma concepção racional da ordem jurídica, definida pelas leis, nas quais a administração deve estar pautada.

$\bigcirc$ Estado moderno caracteriza-se através de um meio específico que é o exercício do monopólio da coação física legítima. Outra característica é o território, que estabelece os limites do exercício da coação física. Constitui ainda característica do Estado moderno a burocracia, os funcionários do Estado, que pautam as suas atividades através de regras racionais, gerais e abstratas: a lei emanada do próprio Estado, sendo, portanto, uma atividade impessoal e vinculada. ${ }^{4}$

Assim, para WEBER o Estado é “[...] uma relação de domínio de homens sobre homens baseada por meio da coação legítima (é dizer, considerada legítima)".

Quanto à questão da política e do Estado, JULIEN FREUND inicia a análise das teorizações de WEBER asseverando que "A política é uma atividade geral do ser humano, isto é, está em toda a nossa história". ${ }^{5}$ Aduz ainda que ao longo do tempo ela tomou diversas formas, fundadas em vários princípios e dando legitimidade a várias instituições. Compreendendo-a assim, não podemos confundi-la com o
Estado, que é apenas uma das suas manifestações modernas, decorrente do processo de racionalização. "A política é, pois, anterior ao Estado, mesmo que em nossos dias a atividade política tenda a se reduzir a atividade estatal ou o agrupamento político que reivindica com êxito o monopólio do constrangimento físico legítimo." 6

O objetivo principal de WEBER não é analisar o desenvolvimento histórico do Estado mas, sobretudo, buscar compreender o fenômeno político em geral. Tal escopo se faz necessário, pois o uso legítimo da força pode ocorrer em outros agrupamentos que não uma associação política, tais como a comunidade doméstica, as corporações ou os feudos. "Weber exprime ainda esta idéia sob outra forma: a unidade política sempre constituiu um agrupamento (Verband) e foi só em nossos dias que ela tomou o aspecto de uma instituição (Anstalt) rígida. É pois, a natureza específica do agrupamento político que é preciso explicar, para se apreender o fenômeno político em si mesmo."7

Recordando o que já vimos acerca da categoria dominação, WEBER define o que é associação política dizendo que "Uma associação de dominação deve chamar-se associação política quando e na medida em que sua existência e a validez de suas

4 SÉRGIO PAULO ROUANET, op. cit., p. 231 sintetiza as características do Estado moderno: "[...] O Estado moderno se organiza com base num sistema tributário centralizado, num poder militar permanente, no monopólio da legislação e da violência e principalmente numa administração burocrática racional".

5 FREUND, Julien. Sociologia de Max Weber. 4. ed., Rio de Janeiro: Forense-Universitária, 1987, p. 159.

6 FREUND, Julien. op. cit., p. 159.

7 FREUND, Julien. op. cit., p. 160. 
ordenações, dentro de um âmbito geográfico determinado, estejam garantidas de um modo contínuo pela ameaça e aplicação da força física por parte do seu quadro administrativo". 8

WEBER assevera ainda que "Um dos mais importantes campos da associação compulsória é o controle das áreas territoriais".

Antes de estabelecer o liame entre a política e o Estado, é importante elucidar os estudos de WEBER no tocante à atividade política.

A atividade política é assim definida por JULIEN FREUND, a partir das teorizações de MAX WEBER:

"A atividade política se define, em primeiro lugar, pelo fato de se desenrolar no interior do território delimitado. Não é necessário que as fronteiras sejam fixadas rigorosamente; podem ser variáveis; entretanto, sem a existência de um território que particularize o agrupamento, não se poderia falar em política. Disso decorre a separação característica entre o interior e o exterior, qualquer que seja a forma da ordem interior ou a das relações exteriores. Esta separação é inerente ao conceito de território. Em segundo lugar, os que habitam no interior das fronteiras do agrupamento adotam um comportamento que se orienta significativamente segundo esse território e a comunidade correspondente, no sentido em que sua atividade se acha condicionada pela autoridade encarregada da ordem, eventualmente pelo uso do constrangimento e a necessidade de defender a sua particularidade. Ao mesmo tempo, os membros do agrupamento político nele encontram certo número de oportunidades específicas que oferecem novas possibilidades à sua atividade em geral. Em terceiro lugar, o meio da política é a força, eventualmente a violência. Ela utiliza, por certo, todos os outros meios para levar a bom termo seus empreendimentos, porém em caso de falência dos outros processos, a força é a ultima ratio; é o seu meio específico." ${ }^{10}$

JULIEN FREUND analisa as articulações entre a dominação e a atividade política:

"[...] Decorre destas explicações que o domínio (Herrschaft) está no âmago do político como a atividade que reivindica para a autoridade instalada em um território o direito de domínio, com a possibilidade de usar em caso de necessidade a força ou a violência, quer para manter a ordem interna e as oportunidades que dela decorrem, quer para defender a comunidade contra ameaças externas. A atividade política consiste, em suma, no jogo que tenta incessantemente formar, desenvolver, entravar, deslocar ou perturbar as relações de domínio."

8 WEBER, Max. Economia y Sociedad. 2. ed., México: Fondo de Cultura Económica, 1964, p. 43.

9 WEBER, Max. The theory of social and economic organization. p. 151-162, apud DREYFUSS, René. Política, poder, Estado e força: uma leitura de Weber. 2. ed., Petrópolis: Vozes, 1993, p. 67.

10 FREUND, Julien. op. cit., p. 160-161.

11 FREUND, Julien. op. cit., p. 161. 
Segundo as teorizações weberianas até aqui apresentadas, como podemos observar, a questão da territorialidade é crucial em se tratando de Estado e da política, dentro da perspectiva moderna. ${ }^{12}$

Podemos concluir que a política na modernidade estava centrada no Estado, ou seja, era dentro dos limites territoriais do Estado que a ela se manifestava.

Antes de abordarmos a política na pós-modernidade, iremos analisar algumas experiências contemporâneas que nos permitirão identificar algumas características da situação pós-moderna.

Segundo KRISHAN KUMAR, a pós-modernidade "[...] apaga as linhas divisórias entre os diferentes reinos da sociedade - político, econômico, social e cultural". ${ }^{13}$ Esta manifestação nada tem de sui generis, eis que as teorizações de DURKHEIM e MARX ${ }^{14}$ no século XIX, já contemplavam a interconexão entre os diferentes reinos da sociedade.
A pós-modernidade funde os diferentes reinos da sociedade e o faz de modo peculiar, assim identificado por KUMAR:

"[...] Não são negados o pluralismo e a diversidade irredutíveis da sociedade contemporânea. [...] Esse pluralismo, contudo, não é organizado e integrado de acordo com qualquer princípio discernível. Não há, ou pelo menos não há mais, qualquer força controladora e orientadora que dê a sociedade forma e significado nem na economia, como argumentaram os marxistas, nem o corpo político, como pensaram os liberais, nem mesmo, como insistiram os conservadores, na história e na tradição. Há simplesmente um fluxo um tanto aleatório, sem direção, que perpassa todos os setores da sociedade. As fronteiras entre eles se dissolvem, resultando, contudo, não em uma totalidade neoprimitivista, mas em uma condição pós-moderna de fragmentação."15

Resgatando o que vimos até aqui, constatamos que a pós-modernidade rompe as fronteiras entre as várias dimensões da vida social, decorrendo um pluralismo, ${ }^{16}$ que

12 JULIEN FREUND, op. cit., p. 161-162 é enfático acerca da característica peculiar da política no âmbito do Estado moderno: "[...] Nem o poderio nem o domínio são peculiares apenas ao político, já que existem outras circunstâncias ou necessidades (economia, pedagogia), em que o homem é igualmente levado a fazer triunfar a sua vontade. Tornam-se políticas quando a vontade se orienta significativamente em função de um agrupamento territorial, com vistas a realizar um fim, que só tem sentido pela existência desse agrupamento. [...] na base de todo domínio político existe a relação fundamental do mando e da obediência. [...] 0 mando é, por sua natureza, fator de organização do agrupamento; em nossos dias, ele se exerce em geral com base em uma organização fortemente estruturada, graças à presença de uma administração, de um aparelho permanente de constrangimento de regulamentos racionais, etc., que são como garantias de continuidade da atividade política. Esta situação, entretanto, é característica apenas do Estado moderno e não da política em geral, pois existiram agrupamentos políticos sem nenhuma administração instituída e outros em que o serviço político era prestado por escravos ou por pessoas ligadas pessoalmente ao soberano".

13 KUMAR, Krishan. Da sociedade pós-industrial à pós-moderna: novas teorias sobre o mundo contemporâneo. Rio de Janeiro: Zahar, 1997, p. 113.

14 MARX ligou a superestrutura (a política, a religião e a cultura) à base econômica (infra-estrutura).

15 KUMAR, Krishan. op. cit., p. 113-114.

16 AGNES HELLER e FERENC FEHÉR, na obra A condição política pós-moderna, Rio de Janeiro, Civilização Brasileira, 1998, p. 16, fazem a seguinte leitura do pluralismo presente na pós-modernidade: "A condição política pós-moderna se baseia ma aceitação de culturas e discursos. O pluralismo (de vários tipos) está implícito na pós-modernidade como projeto. 0 colapso da grande narrativa é um convite direto à coabitação entre várias pequenas narrativas (locais, culturais, étnicas, religiosas, 'ideológicas'). 
perpassa todos os setores da sociedade, resultando em fragmentação. ${ }^{17}$

Esta ruptura das fronteiras nos diferentes reinos da sociedade também se apresentará no âmbito do Estado e na política, uma vez que poderemos constatar que a condição pós-moderna implica a metamorfose da política, na medida em que a política da pós-modernidade tem como característica marcante a desterritorialização.

A manifestação mais eloqüente da desterritorialização encontra-se no fenômeno da globalização. ANTHONY GIDDENS define a globalização "[...] como a intensificação das relações sociais em escala mundial, que ligam localidades distantes de tal maneira que os acontecimentos locais são modelados por eventos ocorrendo a muitas milhas de distância e vice-versa". ${ }^{18}$

Observamos que a globalização econômica que vivenciamos é peculiar pela velocidade, extensão, interconexão da movimentação de mercadorias e informações ao redor do mundo, nunca antes visto na história. Tais fatores contribuíram para o aumento da internacionalização do comércio, produzindo um crescimento gigantes- co no comércio mundial, em tal proporção que tornou os Estados impotentes para controlar os fluxos de capitais, cuja dinâmica rompe ou ultrapassa as fronteiras estatais, fazendo com que as fronteiras nacionais começassem a perder sentido. Neste contexto, as empresas transnacionais tornamse protagonistas privilegiados no mundo globalizado, em face do poder por elas detido, fazendo frente ao poder dos Estados. Surge uma nova divisão internacional do trabalho, a qual contribui para o reforço deste poder, fazendo com que a produção se dissemine em vários países, tornando obsoletas as fronteiras dos Estados e reduzindo o seu poder.

OCTAVIO IANNI assevera que a desterritorialização tem o condão de fazer com que a sociedade global ingresse na pósmodernidade:

"À primeira vista, a desterritorialização lança a idéia da sociedade global no cerne da pós-modernidade. Aí muita coisa muda de figura, desloca-se, flutua, adquire outro significado, dissolve-se. Ao lançarse além dos territórios, fronteiras, sociedades nacionais, línguas, dialetos, bandeiras, moedas, hinos, aparatos estatais, regimes

Essa coexistência, porém, pode assumir formas extremamente diferentes. Pode aparecer como a completa indiferença relativista das respectivas culturas umas pelas outras. Pode manifestar-se como a adoração inteiramente falsa 'do outro'('o terceiro-mundismo' dos intelectuais do primeiro mundo). Pode vir acompanhada de total negação, e também pela revitalização, de proposições universais. 0 sentido da rejeição total do universalismo se evidencia por si mesmo. Deve-se observar, porém, que 0 'antiuniversalismo holístico' (uma posição altamente contraditória em seus próprios termos) se combina com outros dois termos negativos: o 'anti-humanismo filosófico' e uma interpretação específica da post-histoire, em que este termo significa a negação, e não apenas o fim, da história. [...]".

17 Acerca da fragmentação presente na sociedade pós-moderna, aduz SÉRGIO PAULO ROUANET, op. cit., p. 234: "Essa é a característica comum de todas as descrições da sociedade pós-moderna: o social como um fervilhar incontrolável de multiplicidades e particularismos, pouco importando se alguns vêem nisso um fenômeno negativo, produto de uma tecnociência que programa os homens para serem átomos, ou outros um fenômeno positivo, sintoma de uma sociedade rebelde a todas as totalizações - ou o terrorismo do conceito, ou o da polícia".

18 GIDDENS, Anthony. As conseqüências da modernidade. São Paulo: UNESP, 1991, p. 69. 
políticos, tradições, heróis, santos, monumentos, ruínas, a sociedade global desterritorializa quase tudo o que encontra pela frente. E o que se mantém territorializado já não é mais a mesma coisa, muda de aspecto, adquire outro significado, desfigura-se. Rompem-se os quadros geográficos e históricos prevalecentes de espaço e tempo. Emergem outras conotações para que é singular, particular, universal, em outras mediações. Os quadros mentais de referência, fortemente enraizados na hipótese da sociedade nacional, do Estado-Nação, adquirem outras possibilidades de expressão. Rompem-se os significados dos conceitos, categorias, leis e interpretações codificados nas noções da sociedade civil, Estado nacional, povo, cidadão, classe social, grupo étnico, movimento social, partido político, corrente de opinião pública, diversidades, desigualdades, antagonismos.

De forma inesperada, o simulacro aparece no lugar da realidade, vida, formas de ser, viver e sentir, agir, pensar, sonhar e imaginar. $\mathrm{O}$ mesmo processo de desenraizar e desterritorializar produz o fetichismo das coisas, gentes e idéias, das relações sociais, modos de pensar, imaginar. Tudo que é social descola-se do tempo e do lugar, conferindo a ilusão de outro mundo. [...]

É assim que a desterritorialização aparece como um momento essencial da pós-modernidade, um modo de ser isento de espaços e tempos, no qual se engendram espaços e tempos inimagináveis. É como se o mundo se mostrasse povoado de sucedâneos, simulacros, fetiches autonomizados, reificados, alheios ao cerne das coisas, isentos da tensão e da aura real."19

A metamorfose da política na sociedade pós-moderna foi brilhantemente descrita por SÉRGIO PAULO ROUANET:

"[...] Enquanto a política moderna tinha como palco o Estado e visava a conquista e a manutenção do poder estatal, a política pós-moderna tem como palco a sociedade civil e visa a conquista de objetivos grupais ou segmentares. Os sujeitos da nova política não são mais os cidadãos, mas grupos, e seus fins não são mais universais, visando o interesse geral, mas micrológicos. O citoyen rousseauista, abstração social sem biografia, pulveriza-se em seus elementos constitutivos e é restituído à sua particularidade de mulher e judeu, negro e homossexual, e conseqüentemente a política não é mais a genérica, exercida pelo cidadão, mas a específica, de quem está inscrito em campos setoriais de dominação - a dialética homem/mulher, anti-semita/judeu, etnia dominante/ etnias minoritárias.

Assim como não há atores políticos universais - grandes partidos agregando um leque amplo de interesses e posições -, não há mais um 'poder' central, localizado no Estado, mas um poder difuso, estendendo sua rede capilar por toda a sociedade civil - as 'disciplinas' de Foucault. Política segmentar, exercida por grupos particulares, política micrológica, destinada a combater o poder instalado nos interstícios mais imperceptíveis da vida cotidiana, estamos longe da po- 
lítica moderna, em que o jogo político se dava através de partidos, segundo os mecanismos da democracia representativa." ${ }^{20}$

KRISHAN KUMAR faz uma leitura da perspectiva espacial da sociedade pósmoderna, mostrando a imbricação do global e do local:

"A sociedade pós-moderna associa tipicamente o local e o global. Os acontecimentos globais - a internacionalização da economia e da cultura - são refletidos para as sociedades nacionais, minando as estruturas nacionais e promovendo as locais. A etnicidade recebe um impulso renovado. Ocorre um ressurgimento do regionalismo e dos 'regionalismos periféricos' - o nacionalismo de pequenas nações incorporadas a unidades mais amplas, como o Reino Unido, a França, a Espanha e outros agrupamentos nacionais históricos. 'Pense globalmente, aja localmente', o lema da década de 1960, aplica-se a um bom número de novos movimentos sociais, sobretudo aos movimentos feminista e ecológico. Uma vinculação semelhante ocorre em alguns dos novos movimentos de revivência religiosa, tais como o fundamentalismo protestante e o islâmico." ${ }^{21}$

Como vimos anteriormente, as várias dimensões da vida social (a política, a economia e a cultura) são influenciadas por acontecimentos que ocorrem em âmbito global, que implicou uma "[...] renovada importância ao local e a uma tendência para estimular culturas subnacionais e regionais". 22

Em decorrência de tais peculiaridades, vamos constatar que a condição política pós-moderna, na visão de KUMAR, pode ser identificada nas seguintes manifestações:

"As instituições e práticas típicas da nação-estado são correspondentemente debilitadas. Os partidos políticos cedem lugar a 'novos movimentos sociais' baseados em sexo, raça, localização, sexualidade. As 'identidades coletivas' de classe e experiência compartilhadas de trabalho dissolvem-se em formas mais pluralizadas e específicas. A idéia de uma cultura e de uma identidade nacionais é atacada em nome de culturas 'minoritárias' - as culturas de grupos étnicos, de seitas religiosas e comunidades específicas, baseadas na idade, sexo e sexualidade. O pós-modernismo destaca sociedades multiculturais e multiétnicas. Promove a 'política da diferença'. A identidade não é unitária nem essencial, mais fluída e mutável, alimentada por fontes múltiplas a assumindo formas múltiplas (não há distinções tais como 'mulher' ou 'negro')."23

AGNES HELLER e FERENC FEHÉR ${ }^{24}$ destacam o caráter negativo da

20 ROUANET, Sérgio Paulo. op. cit., p. 237.

21 KUMAR, Krishan. op. cit., p. 132-133.

22 KUMAR, Krishan. op. cit., p. 132.

23 KUMAR, Krishan. op. cit., p. 132.

24 É importante destacar a leitura que os autores têm da condição política pós-moderna, a qual é apresentada na op. cit., p. 23: "Será o que chamamos 'condição política pós-moderna' um novo período da política? Temos de reiterar o que vimos sugerindo desde o início: a pós-modernidade é em todos os sentidos 'parasítica' da modernidade; vive e alimenta-se de duas conquistas e 
condição política pós-moderna, eis que a política estaria impregnada de irracionalidade e imprevisibilidade no tocante à questão nacional:

"[...] Mas as políticas baseadas no interesse têm uma excelente tendência racional: são calculáveis e, como tal, mais ou menos previsíveis. Nesse sentido, os frutos da condição pós-moderna são quase inteiramente negativos, na medida em que a política e a mudança política se tornaram quase inteiramente irracionais e imprevisíveis. A relativa parcela de nacionalismo, um fator de racionalidade invariavelmente dúbio, continuou sendo uma constante, para dizer o mínimo. Essa parcela talvez tenha aumentado. Pior, sua função mudou. Pois há muita verdade no velho truísmo marxista de que a 'questão nacional' foi, até a fundação dos modernos estados nações, em grande parte uma questão de classe. Contudo, assim que surgiram os estados nações, a ênfase ao componente nacional, tão visível na condição política pós-moderna, intensificou o elemento irracional na política pós-moderna. $O$ racismo que se acreditava morto depois de Hitler, tornou-se mais uma vez uma questão politizada, e isso não está inteiramente desvinculado do relativismo pós-moderno, que solapou o senso de tabu. $\mathrm{O}$ 'componente de etnicidade' da política, que parecia ter sido varrido pela existência do estado nação, tornou-se mais uma vez um conflito explosivo."25
A fim de que a análise ora realizada não se restrinja a uma mera descrição da condição política pós-moderna, iremos concluir nossa reflexão realizando uma breve abordagem crítica das conseqüências negativas da configuração política engendrada pela pós-modernidade. Para tanto, iremos contextualizar nossa leitura a partir do fenômeno da globalização, onde vislumbramos as manifestações pós-modernas no âmbito da política.

Primeiramente, é importante resgatar o que OCTAVIO IANNI asseverou que a desterritorialização lança a idéia da sociedade global no cerne da pós-modernidade. Portanto, a peculiaridade da política na pósmodernidade cinge-se ao processo de transnacionalização do espaço político decorrente da globalização, quando a noção de política perde o seu referencial de manifestação num espaço definido territorialmente, transcendendo as fronteiras do Estado.

No tocante à tendência da globalização reforçar a importância do local, entendemos que tal peculiaridade não se manifesta no âmbito da política local. Vislumbramos que com a globalização o espaço público está se esvanecendo na medida em que as decisões transcendem o âmbito do Estado, máxime quando definidas pelas empresas transnacionais e organismos

seus dilemas. O que é novo na situação é a inédita consciência histórica surgida na post-histoire; o sentimento grassante de que vamos ficar sempre no presente do que jamais fizemos, além de criarmos um distanciamento crítico dele. E quem continua insatisfeito com apenas esse tanto de distanciamento crítico de nossas perspectivas políticas deve lembrar que a negação absoluta do presente (inegavelmente mais do que poderia oferecer a pós-modernidade) com toda a probabilidade acabaria ou em total perda de liberdade ou em total destruição". 
internacionais, implicando o enfraquecimento do poder local (Estado-nação) e produzindo apatia política, uma vez que a participação política dos cidadãos cada vez mais perde significância, eis que o indivíduo sente-se distante dos centros decisórios, que se encontram fora do lugar onde vive.

Vimos anteriormente que dentre as manifestações da sociedade pós-moderna, vamos identificar a fragmentação e o individualismo, os quais entendemos que causam efeitos nefastos na política. No contexto do mundo globalizado, os cidadãos acabariam assumindo a condição de consumidores, ensejando comportamentos egoístas, despertando o individualismo, rompendo os elos de solidariedade social e de compartilhamento de um destino comum na sociedade, peculiaridade que poderá resultar na fragmentação progressiva da sociedade e no perecimento da política. ${ }^{26}$
Constataremos ainda na sociedade global a existência de uma crescente exclusão social, caracterizada pela precarização das condições de trabalho, pela disseminação do desemprego crônico, baixos níveis salariais, perda das garantias sociais dos cidadãos e pela geração de um quadro de pobreza estrutural, que compromete a participação dos cidadãos nos âmbitos político e jurídico, eis que os cidadãos não têm garantidas condições mínimas e dignas de existência para participarem politicamente.

Refletir a condição política pós-moderna, constitui uma oportunidade para pensar o mundo que vivemos, tomando consciência nosso presente e das estratégias para debelar as vicissitudes do nosso cotidiano. Sem ter a pretensão de esgotar a temática, as reflexões aqui apresentadas visaram instigar o leitor a participar no debate das questões ora suscitadas e de outras que delas decorrerem.

26 AGNES HELLER e FERENC FÉHER, op. cit., p. 23, destacam a prevalência do critério econômico sobre o político na tomada das decisões: "[...] $O$ aspecto negativo da atual situação refere-se à problemática divisão dos trabalhadores entre partidos e movimentos. Nas últimas décadas, nas políticas ocidentais, os partidos se tornaram quase exclusivamente agências econômicas, enquanto se atribuía aos movimentos o papel de forjar opções políticas. Em conseqüência disso, as eleições se concentram, quase sem exceção, em problemas econômicos. [...]". 